\title{
Study on Energy Saving of the Secondary Regulation Load Simulation System
}

\author{
Zhang Chunyu \\ Hebei Provincial Key Laboratory of Heavy Machinery \\ Fluid Power Transmission and Control \\ Yanshan University \\ Qinghuangdao, China \\ e-mail: cyzhang@ysu.edu.cn
}

\author{
Zhu Xiaoxia \\ Beijing Nuclear Power Design Institute \\ Harbin Electric Company Limited \\ Harbin,China \\ e-mail: 53753896@qq.com
}

\begin{abstract}
Speed and torque load simulation experiment is used widely. Usually, driving department and load department in this experiment system are all energy consumption equipment. Secondary regulation technology is good at controlling of speed and torque, and is conducive to improve energy efficiency. In secondary regulation load simulation system, the secondary element that simulate load works at pump state, and it could provide oil with pressure into system, the oil could use to drive driving department .So the load simulation system with secondary regulation have a good energy efficiency. In this paper, we proved the effect of energy saving of the secondary regulation on the vehicle bridge test system.
\end{abstract}

Keywords-secondary regulation; energy saving; load simulation experiment; vehicle bridge

\section{THE EXPERIMENT OF LOAD SIMULATION}

In modern, the experiment of load simulation is widely used for the industrial designing and scientific experiment [1]. The experiment of load simulation creates a similar environment, in which the tested components work. And the components are loaded by alternate, cycle load [2]. The experiment of load simulation is an important method for the researching in laboratory.

In the loading experiment of rotating machinery's transmission, speed and torque are main parameters to be controlled. Usually, two end of the transmission mechanism are input and output. One end works at the state of motor and be controlled by speed, the other end works at the state of load and be controlled by torque. In the process of the whole load experiment, the two ends working at motor and load are driven by the energy consumption equipment normally [3]. A lot of energy would be consumed by the experiment system in a long time experiment. If simulated the state of motor and load by secondary regulation system, the situation that the two ends consume energy will be changed, and energy efficiency will be improved. The method of secondary regulation is that, in constant pressure network by the way of regulating the output volume of secondary element to control the parameters of speed, angle and torque loading on the tested components. At the end working at load of torque, secondary element work at pump state, and it would output hydraulic pressure to the constant pressure network[4]. So the energy efficiency has a good advance.

\section{SECONDARY REGULATION TECHNOLOGY}

Secondary element is the core component of secondary regulation system. The secondary regulation system mainly works in the way of regulating the volume of secondary element and changing the direction of rotation of secondary element's shaft to achieve energy-saving. There is an obvious difference between the secondary element and variable pump or motor. The difference is that the secondary element could change its work state from pump to motor or in turn, without changing the direction of rotation of its shaft, but altering its swash plate angle in the range of $\pm 15^{\circ}$.

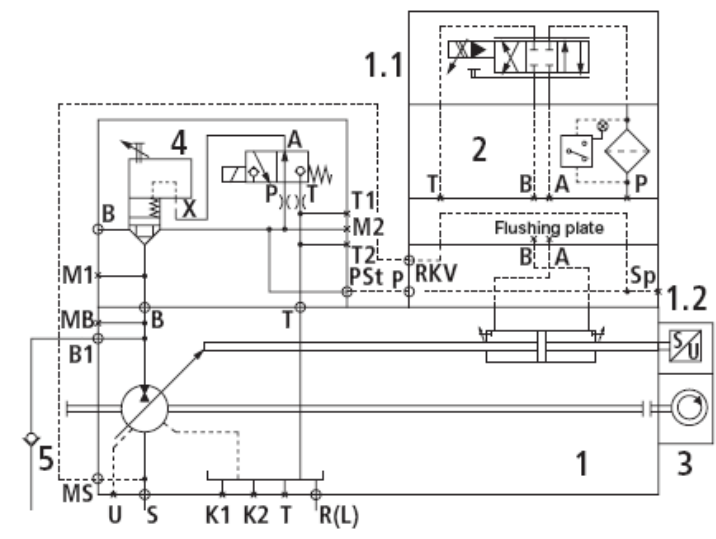

Figure 1. Hydraulic theory structure of secondary unit

Fig .1 shows the theory of secondary element. Element 1 is the pump body of the secondary element. 2 is a filter, its main role is filtering the oil into servo valve. 3 is a encoder, it could record the pulses which come from secondary element's turning, then to control the angle and speed.4 is an on-off valve, it could control oil in or out secondary element.1.1 is a servo valve which use to control the driving cylinder of swash plate and alter angle of the swash plate.

The Structure of secondary element is a swash plate axial piston pump/motor. Its output torque is proportional to its swash plate's angle, and its volume is equal to the sum of the volume of all pistons working a round. 


$$
V_{2}=\left(\frac{\pi}{4} d_{z}^{2}\right) x_{p} Z
$$

In the formula,

V2 - volume of secondary element $(\mathrm{cm} 3 / \mathrm{r})$

$x_{\mathrm{p}}$-displacement of the driving cylinder of swash

plate(mm), $x_{\mathrm{p}}=D_{\mathrm{f}} \operatorname{tg} \alpha$

$d_{Z}$-diameter of the piston of secondary element(mm)

$\mathrm{Z}$ - piston number of secondary element

In theory, the output torque is proportional to the angle of swash plate ,that is

$$
M_{2}=\left(\frac{p_{\mathrm{s}}}{2 \pi}\right)\left(\frac{\pi}{4} d_{\mathrm{z}}^{2}\right) D_{\mathrm{f}} Z(\operatorname{tg} \alpha)
$$

Because the angle of swash plate of axial piston pump is small, its radian value and tangent value is approximately equal, we could use $\alpha$ instead of $\operatorname{tg} \alpha$ [3].so, the formula above could be written in this form,

$$
M_{2}=\left(\frac{p_{\mathrm{s}}}{2 \pi}\right)\left(\frac{\pi}{4} d_{\mathrm{z}}^{2}\right) D_{\mathrm{f}} Z \alpha=K_{D} \alpha
$$

In this way, we can achieve the purpose of controlling the output torque by regulating the swash plate angle with a small flow servo mechanism, so as to realize the torque control, speed control and power control.

In the theoretical calculation, the main parameters of secondary element calculated as follows.

The output flow of secondary element:

$$
q_{2}=\frac{V_{2} \cdot n \cdot \eta_{V}}{1000}
$$

The driving torque of secondary element:

$$
M_{2}=\frac{1.59 \cdot V_{2} \cdot \Delta p}{100 \eta_{m}}
$$

The driving power of secondary element:

$$
P=\frac{60 M_{2} \cdot n}{2 \pi} \times 10^{-3}=\frac{M_{2} \cdot n}{9549}
$$

In the formula

$\Delta p$-Entrance and exit pressure difference of secondary element(bar)

$\mathrm{n}$ - speed of secondary element (rpm)

$\eta_{\mathrm{v}}$ - volumetric efficiency of secondary element

$\eta_{\mathrm{m}}$ - mechanical efficiency of secondary element

$\eta_{\mathrm{t}}$-overall efficiency of secondary element

We can see that the volume of secondary element is proportional to its swash plate's angle. Changing swash plate's angle could control its volume, thereby changing the output torque.

\section{EXPERIMENT SYSTEM OF LOAD SIMULATION WITH SECONDARY REGULATION}

Fig .2 shows the theory of speed and torque load simulation system with secondary regulation. In the Fig .2, element 2 is a constant pressure pump. It provides the constant hydraulic power to the whole experiment system. Element 3 is a accumulator, it works for the pressure fluctuation and instantaneous flow peak. Element 8 is a secondary element working at the input end of the tested component, and input speed into the tested component as a motor state. By speed closed-loop control, servo valve 5 control the driving cylinder 6 of swash plate and alter angle of the swash plate .The angle decide the output torque of the motor , and make the torque to fit the requirements of the curve of speed control [5,6]. Element 11 is a secondary element too .It works at pump state, and provide load to the tested component. By torque closedloop control, when the output pressure of the pump equal to the system's constant pressure ,altering the output volume of element 11 would realize different driving torque to meet the demanded load[7].

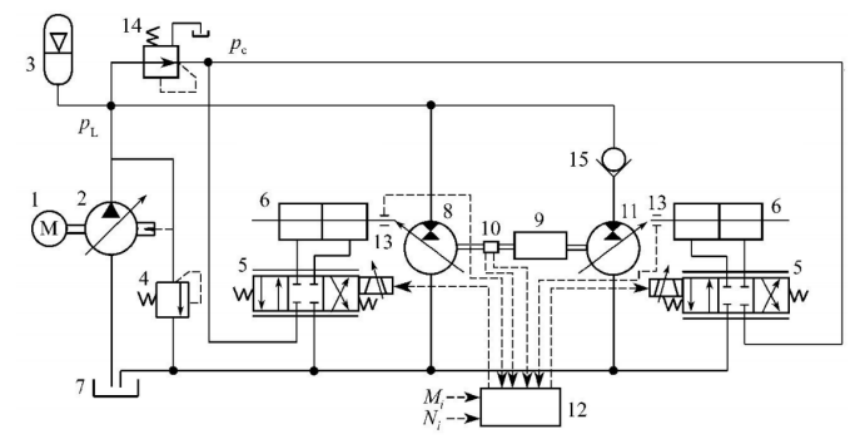

1. Electric motor 2. Constant pressure pump 3. Accumulator 4. Safety valve 5.Electro-hydraulic servo valve 6.Controlling cylinder 7. Tank 8. Secondary element (driving motor) 9. Tested component 10 . Torque and speed sensors 11 . Secondary element (loading pump) 12. Controller 13. Linear displacement sensor 14. Pressure reducing valve 15 . One-way valve

Figure 2. Schematic diagram of a torque servo loading equipment with secondary regulation.

\section{VEHICLE BRIDGE TEST SYSTEM}

With secondary regulation technology, we build a vehicle bridge test system , and make simulation experiment of the vehicle running .In the test system, the driving department use speed control , and drives left and right hubs through gear-box [3]. The loading department works in torque closed-loop control. The system pressure is provided by a constant pressure pump, the maximum output volume of which is $63 \mathrm{ml} / \mathrm{r}$. The output pressure of the pump is set at $4.5 \mathrm{MPa}$. The output volume of secondary element is $40 \mathrm{ml} / \mathrm{r}$. Volume of accumulator in this system is $25 \mathrm{~L}$, and charging pressure is $3 \mathrm{MPa}$. Speed sensor is a encoder, its resolution is $1200 \mathrm{p} / \mathrm{r}$. We set the speed of driving department $600 \mathrm{r} / \mathrm{min}$,and the loading department load is $20 \mathrm{Nm}$. Control characteristic curve of this system show in Fig .3, Fig .4 and Fig.5. 


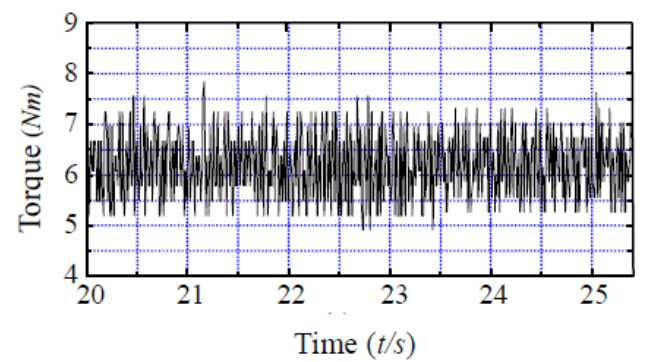

(a) Torque of driving department

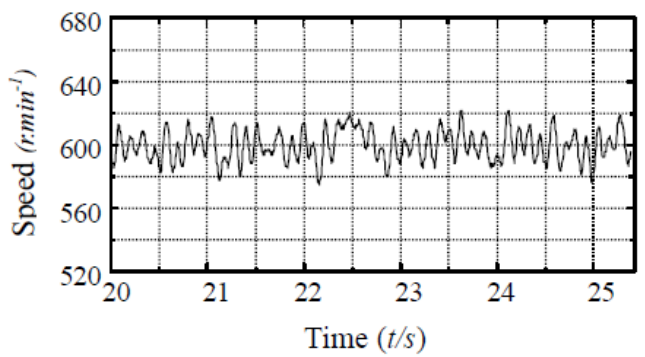

(b) Speed of driving department

Figure 3. The speed and torque curve of the driving department

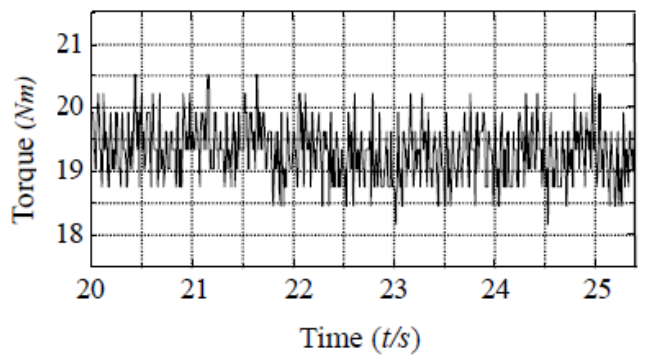

(a) Torque of right wheel

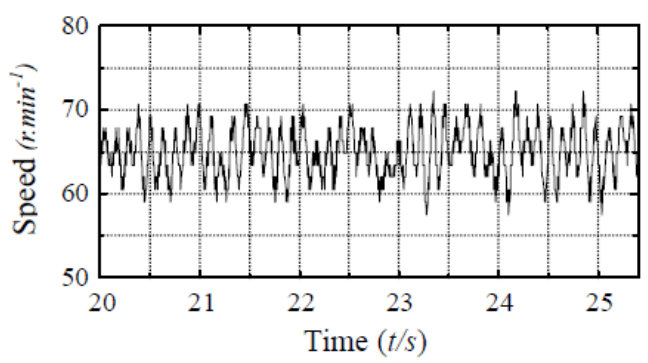

(b) Speed of right wheel

Figure 4. The speed and torque curve of the right wheel

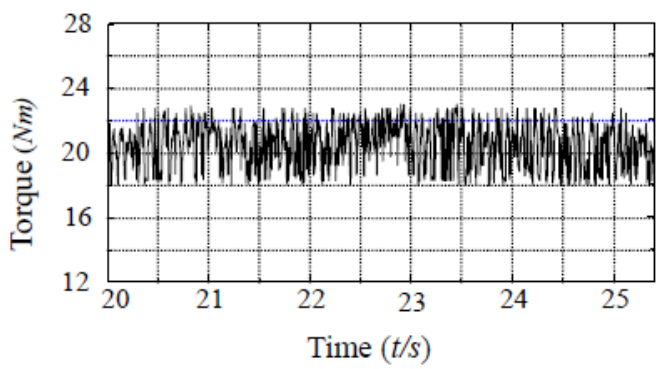

(a) Torque of left wheel

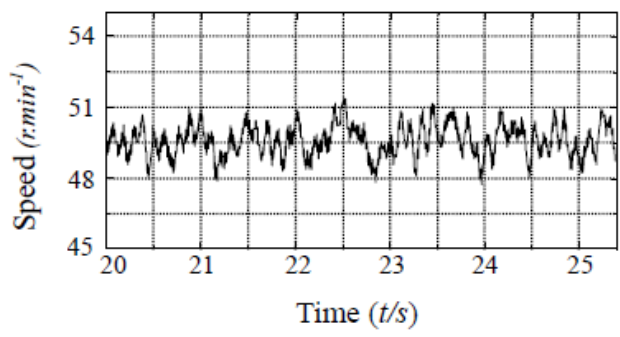

(b) Speed of left wheel

Figure 5. The speed and torque curve of the left wheel

From the curve of the experiment, we know that the vehicle bridge test system with secondary regulation could run stably at the setting target value. The speed control error of the driving department is very small, and the output torque of the loading department is close to the given .

When the experiment system is running, the pressure curve of the system show in Fig .6.

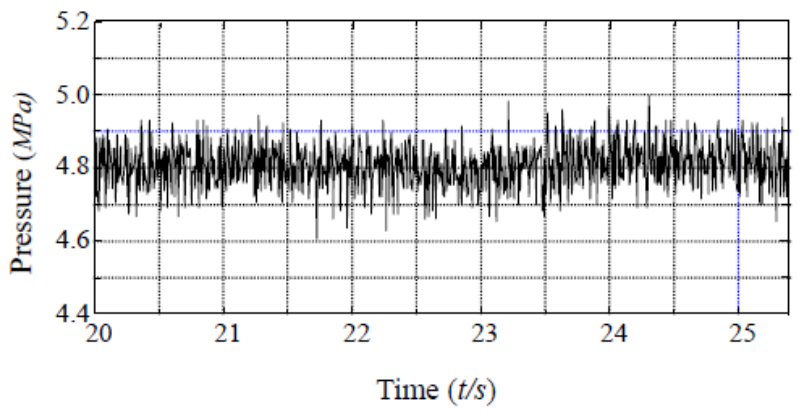

Figure 6. The pressure of the hydraulic system

Show in the Fig .6, in the process of the system running, the pressure of system keep at the point of the constant pressure pump working at. The whole system become a constant pressure network [8]. For the three sets of secondary element in this system all work in constant pressure network, the secondary element of the driving department works at motor state, and the one of the loading department works at pump state, so the vehicle bridge test system with secondary regulation content vehicle bridge loading simulated experiment, and have a good energy efficiency[9,10]. Energy saving become true.

If the influence of power loss on the piping and others don't take in account, the driving power curve and output power curve of the driving department and the constant pressure pump of the system show in Fig .7.Curve 1 is driving power of system, and curve 2 is output power of constant pressure pump. We can see, the power consumption of driving department is about $0.38 \mathrm{~kW}$, but output power of pump is $0.18 \mathrm{~kW}$. The drive energy is larger than the output energy of pump, extra energy come from secondary element of the loading department. The experiment system achieves the purpose of energy saving, and the energy saving efficiency is about $52 \%$. 


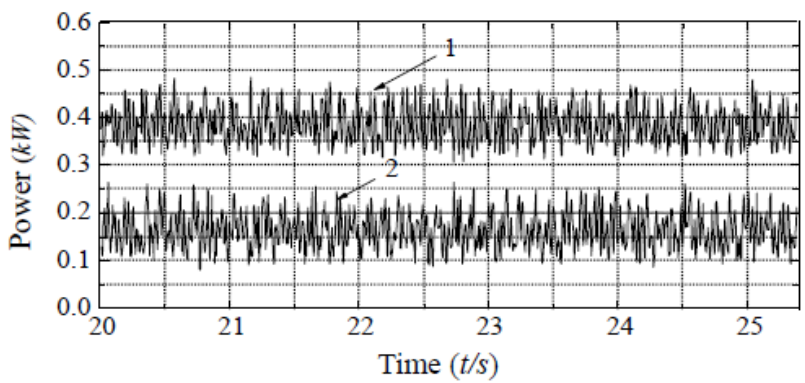

Figure 7. Comparison of the drive power and the output power

\section{CONCLUSIONS}

In the experiment of vehicle bridge testing, we proved that the secondary regulation technology have a good effect of energy saving in the speed and torque load simulation experiment system. The secondary element of loading department work at the state of pump, and it provide hydraulic pressure to the system to drive the driving department, improve energy efficiency of system effectively.

\section{ACKNOWLEDGMENT}

This work was financially supported by the Qinhuangdao Science and Technology Research and Development Plan (201101A148), and the Fund of Steel Joint Research of Hebei Natural Science Foundation (E2013203126).

\section{REFERENCES}

[1] Wu Zhengyu, "The Design of The Control System of Electric Load Simulator,’Dalian: Dalian Maritime University,2009.

[2] Zhan Xingqun, Zhang Yanhua, Zhao Keding, "Hardware Decouple Methods for Torque-Loading Equipment with Hydrostatic Driving Secondary Regulation Technology," Journal of Shanghai Jiao TongUniversity,vol.11,2000.

[3] He Long, "Study On The Characteristic of Energy Saving and Control of The Inertia Load System Based on Secondary Regulation,"Qinhuangdao: Yanshan University, 2010.

[4] De Coster T, "Parker.Hydraulic hybrids technology[R],"ParkerHannifin Corporation, 2012

[5] Wang Xin, " Research on energy saving and control performanees of wheel drive hydraulic hybrid vehicle[D]," Harbin: Harbin Institute of Technology,2010.

[6] Wu Genmao ,Qiu Minxiu,Wang Qingfeng,Wei Jianhua, "Electrohydraulic Proportional Technique in Theory and Application,"Hangzhou:Zhejiang University Press,2006.9

[7] Gao Peichuan, Sun Menghui, Lv Yunsong, Li Jianqi, “ Research on Energy-saving Technique of Hydraulic Secondary Regulation in Hydraulic Excavator," Coal Technology,vol. 31, 2012,pp.19-20

[8] Ma Dengcheng,Yang Shimin,Ma Denghui ,Jiang Xiaoming, "Study on Applications of Secondary Regulation Technology in Test Bench Loading System," China Mechanical Engineering,vol.25,Nov.2014,pp.1453-1459

[9] Luo Nianning , Zhang Jian , Jiang Jihai, Zhang Qingrun, "Hydraulic Hybrid Technology and Its Research Progress," Machine Tool \& Hydraulics,vol.41,2013,pp.19-25

[10] Wang Haifei, Yao Shuxin, Cao Leilei, Kong Yan,“ Test Device of Construction Machinery Engines Under Dynamic Loading," China Journal of Highway and Transport,vol.27,Jul.2014,pp.118-126. 